\title{
Prediction of Electricity Consumption Demand Pattern for 2018 in Ogun State, Nigeria
}

\section{1*ADE-IKUESAN, OO; ${ }^{1}$ OSIFEKO, MO; ${ }^{2}$ OKAKWU I.K, ${ }^{1}$ FOLARANMI, KS; ${ }^{1}$ ALAO, PO}

\author{
${ }^{1 *}$ Department of Computer and Electrical Engineering, Olabisi Onabanjo University, Nigeria \\ ${ }^{2}$ Department of Electrical/Electronic Engineering, University of Benin, Benin City, Edo State, Nigeria \\ *Corresponding author Email: osifeko.martins@oouagoiwoye.edu.ng
}

\begin{abstract}
This study uses probabilistic load forecast technique to predict the load demand pattern in Ogun State for year 2018. Energy consumption data for Ogun State for year 2016 and 2017 was obtained from the regional headquarter of the Ibadan Electricity Distribution Company (IBEDC), Abeokuta. The results of the study show that the energy consumption in Ogun State has the probability tendency of rising above 98,469.40 MWHR by $2.68 \%$. Similarly, it was also established that the probability of energy consumed in the state rising below 46,494.68 MWHR within the next few months will be $5.98 \%$. The probability that energy consumption in year 2018 will fall between $98,469.40$ MWHR and 46,494.68 MWHR is $91.84 \%$. Energy consumption in year 2018 will mostly fall between 63,500 MWHR $-86,000$ MWHR. The result also indicated that energy consumption in 2018, has the highest probability of falling between 72,500 MWHR and 77,000 MWHR by $15.34 \%$. It is unlikely it falls between 45,000 MWHR to 50,000 MWHR and 95,000 MWHR to 99,500 MWHR, with both range having their percentage probabilities at $0.19 \%$ and $2.99 \%$ respectively. Result of this study is useful to IBEDC for their operational planning and control activities.
\end{abstract}

\section{DOI: https://dx.doi.org/10.4314/jasem.v22i6.7}

Copyright: Copyright (C) 2018 Ade-Ikuesan et al. This is an open access article distributed under the Creative Commons Attribution License (CCL), which permits unrestricted use, distribution, and reproduction in any medium, provided the original work is properly cited.

Dates: Received: 19 April 2018; Revised: 22 June: 2018; Accepted: 30 June 2018

Keywords: energy consumption forecast, probabilistic load forecast (PLF), deterministic forecast

To forecast means to predict with the aid of previous or past data. Thus, energy forecasting refers to all forms of forecasting done in the energy industry which includes but is not limited to the forecasting of the supply, demand and price of electricity, gas, water, and renewable energy (Hong et al., 2016). Forecasting plays an important role in power system planning operation, control as well as energy management (Atul and Suganthi, 2017; Hong, 2014). Load forecasting, a form of energy forecasting is the process of predicting the electric demand at certain geographical and/or temporal interval into the future. Load forecasts is used in utilities' operational/planning process (Xie, 2016) and could either be carried out on a short, medium and long-term basis. Short and medium-terms forecast refers to a forecast done over half an hour to few hours and a few days to few weeks respectively while long-term forecast is done over a period of 1 week to 1 year or more ahead (Sepasi et al., 2017). Lately, due to geometric increase in the global demand for energy, long-term load forecasting became more important and interesting to the industrial and research community. Another interesting aspect of energy forecasting is the techniques used in carrying out the forecast. Techniques can be classified as Deterministic (wherein a single value is obtained), Probabilistic (based on chances) or Stochastic (random). Over the last decade, an increase in market competition, aging infrastructure and renewable integration requirements have made PLF increasingly important for the planning and operation of energy systems. Compared to traditional point load forecasting, probabilistic load forecasting (PLF) has great significance in advanced system scheduling and planning with higher reliability (Gan et al., 2018). PLFs can be used for stochastic unit commitment, power supply planning, probabilistic price forecasting, the prediction of equipment failure, and the integration of renewable energy source (Gerossier et al., 2017; Hong and Fan, 2016).

In (Shepero et al., 2018), probabilistic and deterministic error metrics were evaluated for the lognormal process (LP) and compared to the conventional gaussian process (GP). The results showed that the LP produced sharper forecasts compared with the conventional GP. In another related study (Gan et al., 2017), a short-term probabilistic forecasting results in terms of quantiles is presented which can better describe the uncertainty of residential loads. The study used a deep-learning-based method to implement probabilistic residential load forecasting. Results show that the proposed method overrides traditional 
methods significantly in terms of average quantile score. In (Gan et al., 2018), a quantile regression neural network (QRNN) based probabilistic load forecasting was proposed. By considering both input uncertainty and output variation, it turned out that the proposed QRNN model performs better than commonly used benchmark models. In (Gerossier et al., 2017), a probabilistic day-ahead forecasting model is proposed to predict hourly electrical demand from individual households. The proposed model uses smart-meter data and temperature predictions to make quantile forecasts. In the study, performance was evaluated using data from a real-life smart grid and result showed that the proposed model provided reliable probabilistic forecasts.

In Nigeria, energy supply is uncertain and prone to a lot of challenges like vandalism, shortage of gas and the aim of this work is to provide relevant data on the Electricity Consumption Demand Pattern in Ogun State Nigeria for 2018 by leveraging on the tool of strategic forecast. Ogun state, been one of the industrial and commercial nerve center in the country, stands to benefit from proper energy planning activities.

\section{MATERIAL AND METHODS}

Study Area: Ogun State, Nigeria is located between longitude 6058' North and 3056'east of the Greenwich meridian and Latitude 6.97 and 3.93 North of the Equator. Abeokuta is the capital and largest city in the state. The 2006 census recorded a total population of $3,751,140$ residents. The state has six district offices now Business Hubs with the regional office in Abeokuta. There are six Transmission stations within the state, these include Sagamu, Ijebu-ode, Ojere, Papalanto, Ota and Oke-Aro 132/33/11/0.415kv transmission stations. These Transmission station feed $33 \mathrm{kv}$ feeders and 27 Nos injection substations owned by IBEDC which inter supply electricity to 47 Nos $11 \mathrm{kv}$ feeders across the state. The demographic data of Ogun State, Nigeria as contained in the population census of 21st March 2006 is a made up of 1,864,907 males and 1,886,233 Females. The total population stood at $3,751,140$. The projected population for the state in 2010 also stood at 5,217,700. The state has an area of $16,762 \mathrm{~km}^{2}$ while the density stands at $311.3 / \mathrm{k}$ $\mathrm{m}$

Data Collection: The data used in this study was obtained from IBEDC, Ogun regional office, Abeokuta (2016, 2017). It represents the monthly energy consumption (MWh) in Ogun State from January 2016 to December 2017. The obtained data is shown in Table 1, Figure 1 and 2.
Table 1. Monthly Energy Consumption from January 2016 to December 2017

\begin{tabular}{|c|c|c|c|}
\hline$\overline{S / N}$ & Month & year & $\begin{array}{l}\text { Energy Consumption } \\
(\mathrm{MWh})\end{array}$ \\
\hline 1 & January & 2016 & $57,718.26$ \\
\hline 2 & February & 2016 & $64,749.04$ \\
\hline 3 & March & 2016 & $65,006.65$ \\
\hline 4 & April & 2016 & $67,603.08$ \\
\hline 5 & May & 2016 & $74,608.58$ \\
\hline 6 & June & 2016 & $75,499 \cdot 80$ \\
\hline 7 & July & 2016 & $76,333.55$ \\
\hline 8 & August & 2016 & $80,692.52$ \\
\hline 9 & September & 2016 & $72,632.51$ \\
\hline 10 & October & 2016 & $89,268.01$ \\
\hline 11 & November & 2016 & $91,376.52$ \\
\hline 12 & December & 2016 & $98,469.40$ \\
\hline 13 & January & 2017 & $60,726.90$ \\
\hline 14 & February & 2017 & $64,177.89$ \\
\hline 15 & March & 2017 & $58,119.54$ \\
\hline 16 & April & 2017 & $64,163.74$ \\
\hline 17 & May & 2017 & $71,419.89$ \\
\hline 18 & June & 2017 & $73,002.31$ \\
\hline 19 & July & 2017 & $77,151.51$ \\
\hline 20 & August & 2017 & $80,250.82$ \\
\hline 21 & September & 2017 & $77,049.24$ \\
\hline 22 & October & 2017 & $85,623.31$ \\
\hline 23 & November & 2017 & $85,446.10$ \\
\hline 24 & December & 2017 & $95,040.39$ \\
\hline & TOTAL & & $1,806,129.56$ \\
\hline
\end{tabular}

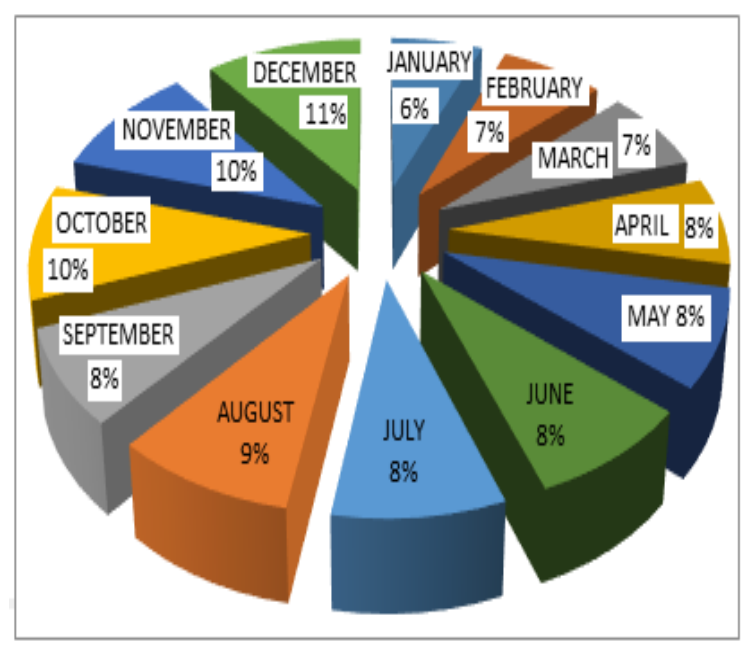

Fig 1. Pie Chart Showing Monthly Energy Consumption in Ogun State for Year 2016

Modelling Equations: With reference to Table 1, the research data is modelled as standard normal distribution data (curve). The equation of standard normal curve is given in (Stroud, 2013) as

$$
\begin{aligned}
& Y=\phi(\mathrm{Z})=\frac{e^{-z / 2}}{\sqrt{2 \Pi}} \\
& Z=\frac{x-\mu}{\sigma}
\end{aligned}
$$


Where, $\mu$ is the mean of monthly energy consumption, $\sigma$ is the standard deviation of monthly energy consumption, $\phi(Z)$ = probability density function in 2016 \& 2017, Z = standard normal variable.

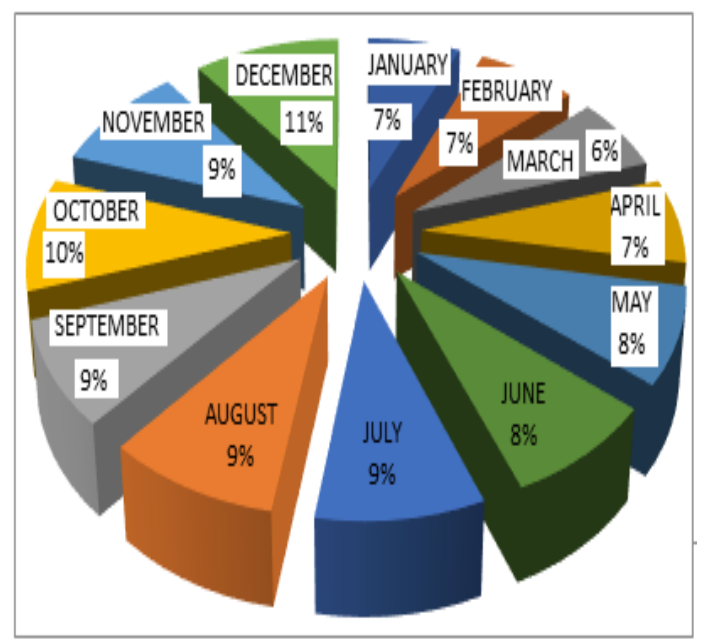

Fig 2. Pie Chart Showing Monthly Energy Consumption in Ogun State for Year 2017

The mean monthly energy consumption may be estimated as

$\bar{X}=\frac{\text { Total monthly energy consumption in } 2016 \text { and } 2017}{\text { No of month }}$

Standard Deviation of Monthly Energy Consumption $\sigma=\sqrt{\frac{\sum(\bar{X}-X)^{2}}{n}}$

\section{RESULT AND DISCUSSIONS}

To analyze the acquired data, Probabilistic calculation and statistical analysis were used. Also, the results of the calculations were analyzed with probabilistic predictions of what the future holds for energy consumption in Ogun state especially in the next few months. From the standard normal distribution table, the probabilities that the monthly energy consumption will fall within some selected ranges of values is as shown in Table 2

A probabilistic analysis was also conducted on the monthly data of energy consumption in 2016 and 2017. Using equation 1 and 2, the probability that the energy consumption will be greater than or equal to 98,469.40MWh is computed as 0.0192 oR $1.92 \%$ while the probability that the energy consumption will be less than or equal to $57,718.26 \mathrm{MWh}$ is computed as 0.0594 or $5.94 \%$. The probability that the energy consumption falls between 57,718.26 $\mathrm{MWh}$ and $98,469.40 \mathrm{MWh}$ in the next few months is computed as 0.9214 OR $92.14 \%$. Note that 98,469.40 MWHR and $57,718.28$ represent the peak and the least energy consumption during Year 2016 and 2017. It can be further stated that there is high tendency that the energy consumption in the state especially in year 2018 can go below 57,718.26 MWHR (5.94\%) than rising above 98,469.70 MWHR (1.92\%). This implies that the probability of energy consumption in 2018 falling below the lowest energy consumption in 2016 and 2017 is thrice the probability of energy consumption rising above the peak consumption (98,469.40MWh) in 2016 and 2017.

Table 2: the probabilities that the energy consumption will fall within some selected range energy consumption.

\begin{tabular}{llll}
\hline S/N & $\begin{array}{l}\text { Range of Energy } \\
\text { consumption }(\mathbf{M W h})\end{array}$ & Probabilities & $\begin{array}{l}\text { \% } \\
\text { Probabilities }\end{array}$ \\
\hline 1 & $95,000-99,500$ & 0.0238 & 2.38 \\
2 & $90,000-95,000$ & 0.0477 & 4.77 \\
3 & $86,000-95,000$ & 0.0816 & 8.16 \\
4 & $81,500-86,000$ & 0.1192 & 11.92 \\
5 & $77,000-81,500$ & 0.1493 & 14.93 \\
6 & $72,500-77,000$ & 0.1617 & 16.17 \\
7 & $68,000-72,500$ & 0.1435 & 14.35 \\
8 & $63,500-68,000$ & 0.1199 & 11.99 \\
9 & $59,000-63,500$ & 0.0644 & 6.44 \\
10 & $54,500-59,000$ & 0.0413 & 4.13 \\
11 & $50,000-54,000$ & 0.02 & 2 \\
12 & $45,000-50,000$ & 0.0087 & 0.87 \\
\hline
\end{tabular}

In fact, it can be formulated that $\mathrm{P}(\mathrm{X} \geq 57,718.26) \approx$ $1.78 \sqrt{3} \mathrm{P}((\mathrm{X} \geq 98,469.40) \mathrm{MWh}$. And peak value $\approx$ $\sqrt{3} *$ deep value. Energy consumption in 2018 will mostly fall between $63,500 \mathrm{MWh}$ to $86,00 \mathrm{MWh}$ particularly between $72,500 \mathrm{MWh}$ to $77000 \mathrm{MWh}$ $(16.17 \%)$.

It is highly unlikely it falls between $45,500 \mathrm{MWh}$ $\approx 50,000 \mathrm{MWh}$ and $95,000 \mathrm{MWh} \approx 99,500 \mathrm{MWh}$. Furthermore, it is noteworthy to say that the peak monthly consumption of the study occurred in Dec 2016 as shown in Table 1 suffice to say that the lowest energy consumption $(57,718.26 \mathrm{MWh})$ took place in January 2016. This is traceable to the acute shortage in gas supply due to pipeline vandalism and theft of distribution/sub-station materials which characterized the period.

Conclusion: This work provides relevant data on the Electricity Consumption Demand Pattern in Ogun State Nigeria for 2018. This study has assisted the Nigerian electricity sector by providing a probabilistic load forecast (PLF) for Ogun State, Nigeria. The result of this work will assist the IBEDC in making informed decision about energy distribution/consumption in Ogun State.

\section{REFERENCES}

Atul, A; Suganthi, L (2017). Forecasting of Electricity Demand by Hybrid ANN-PSO Models. 
International Journal of Energy Optimization and Engineering (IJEOE), 6(4): 66-83.

Gan, D; Wang, Y; Yang, S; Kang, C. (2018). Embedding based quantile regression neural network for probabilistic load forecasting. Journal of Modern Power Systems and Clean Energy, 6 (2), 244-254.

Gan, D; Wang, Y; Zhang, N; Zhu, W (2017). Enhancing short-term probabilistic residential load forecasting with quantile long-short-term memory. IEEE Journal of Engineering 2017(14), $2622-2627$.

Gerossier, A; Girard, R; Kariniotakis, G; Michiorri, A (2017). Probabilistic Day-Ahead Forecasting of Household Electricity Demand. Paper presented at the CIRED 2017 - 24th International Conference on Electricity Distribution, Glasgow, United Kingdom. https://hal.archivesouvertes.fr/hal-01518373

Hong, T (2014). Energy forecasting: Past, present, and future. Foresight: Inter. J. Appl. Forecasting (32): 43-48.
Hong, T; Fan, S; (2016). Probabilistic electric load forecasting: A tutorial review. International Journal of Forecasting, 32(3): 914-938.

Hong, T; Pinson, P; Fan, S; Zareipour, H; Troccoli,; Hyndman, RJ (2016). Probabilistic energy forecasting: Global Energy Forecasting Competition 2014 and beyond. International Journal of Forecasting, 32(3), 896-913.

Sepasi, S; Reihani, E; Howlader, AM; Roose L R; Matsuura, MM (2017). Very short-term load forecasting of a distribution system with high PV penetration. Renewable Energy, 106, 142-148.

Shepero, M; van der Meer; Munkhammar, J; Widén, J (2018). Residential probabilistic load forecasting: A method using Gaussian process designed for electric load data. Applied Energy, 218, 159-172.

Stroud, KA; Booth, DJ (2013). Engineering mathematics. Palgrave Macmillan.

Xie, J (2016). Probabilistic electric load forecasting. The University of North Carolina at Charlotte. 